\title{
Laissez faire, laisser passer: desigualdad estructural laboral y recortes presupuestarios
}

\author{
Laissez faire, laisser passer: \\ Structural Labor Inequality and Budget Cuts
}

JUANA MARÍA GIL RUIZ*

\begin{abstract}
Resumen: El Pacto Europeo por la Igualdad de Género (2011-2020), en el contexto de la Estrategia 2020 deja claro tres áreas de intervención urgente en torno a la desigualdad estructural: desempleo y pobreza, el trabajo de cuidado y la violencia de género. Sin embargo, un análisis con perspectiva de género a los actuales Presupuestos Generales del Estado permite concluir el abandono de la protección de los objetivos europeos rubricados por España, que tienen que ver con el incumplimiento del principio vinculante del gender mainstreaming. Este artículo, partiendo del diagnóstico de la posición de las mujeres en la esfera laboral, analizará el abandono de estas tres áreas de intervención y la consecuente dejación de responsabilidades por parte del Estado español.
\end{abstract}

Palabras clave: Desigualdad estructural, gender mainstreaming, Estado Social, recortes presupuestarios, mercado laboral, ciudadanía.

\begin{abstract}
The European Pact for Gender Equality (2011-2020), in the context of the 2020 Strategy makes clear three areas of urgent intervention on structural inequality: unemployment and poverty, care work and gender violence. However, an analysis with a gender perspective to the current General State Budgets allows to conclude abandoning the protection of the European objectives initialed by Spain, which have to do with non-compliance with the binding principle of gender mainstreaming. This article, based on the diagnosis of the position of women in the labour sphere, will analyze the abandonment of these three areas of intervention and the consequent abandonment of responsibilities on the part of the Spanish State.
\end{abstract}

Keywords: Structural inequality, gender mainstreaming, Welfare State, budget cuts, labour market, citizenship.

Recibido: 11/04/2017. Aceptado: 16/07/2017.

* Catedrática de Filosofía del Derecho de la Universidad de Granada. jgil@ugr.es. Asesora del Instituto Andaluz de la Mujer y Vocal del Observatorio de Violencia de Género. Es Editora de la prestigiosa Revista Anales de la Cátedra Francisco Suárez y Tesorera de la Sociedad Española de Filosofía Jurídica y Política (SEFJP). Merecen destacarse sus investigaciones en torno a Violencia de Género, Políticas de Igualdad, Teoría jurídica feminista y Bioética y Bioderecho. Autora de una copiosa obra, merecen destacarse sus monografías Los diferentes rostros de la Violencia de Género, Dignidad e Igualdad en derechos: el acoso en el trabajo o la galardonada con el Ángeles Durán a la innovación científica, Las nuevas Técnicas Legislativas en España. Los informes de evaluación de impacto de Género, Tirant lo Blanch, Valencia, 2012.

Este trabajo se inscribe en el marco del Proyecto I+D+i del Ministerio de Economía y Competitividad Carencias y alternativas jurídico-políticas al tratamiento de las violencias de género: formación e investigación en Derecho Antidiscriminatorio, DER 2014-57244-R. Responsable principal: Juana María Gil Ruiz. 


\section{Introducción}

Si el conflicto de clases fue un elemento clave para entender la existencia del Estado Social o de Bienestar en el siglo pasado, lo cierto es que el llamado conflicto de Género lo es para la comprensión de la Crisis Global del siglo XXI y enmarca, sin duda, los nuevos desafíos de esta nueva era. Se trata de la expresión más cruda de la crisis sistémica y global en la que estamos inmersos que, a su vez, descansa en una crisis acumulada y multidimensional que afecta a la Sociedad del Trabajo y, cómo no, a la crisis de los cuidados. Sin embargo sorprende que, pese a la urgencia de recuperar este tipo de análisis con perspectiva de género, éstos apenas aparezcan en los discursos dominantes y menos aún en los académico-jurídicos. Y el dilema se reduce a la reflexión -comprometida- de si la situación de las mujeres, en tanto que ciudadanas y más de la mitad de la población, ha cambiado sustancialmente en las últimas décadas o si, por el contrario, aún persiste un importante nivel de desigualdad que cuestiona los valores democráticos.

Los datos hablan por sí solos -apenas se eche un vistazo al contexto socio-laboral- y ponen de manifiesto que las constantes denunciadas por la Teoría jurídica-política feminista insisten y persisten. Las mejoras legales no han traído consigo "mejoras" para las mujeres, sino una peligrosa apariencia de igualitarismo y un reloj hipotecado que obliga a las mujeres a tener que decidir - no haciendo uso de su libre albedrío-, si dedicarse a la función doméstica, si participar en el mercado laboral o, las más atrevidas, si hacerse un hueco en el mundo de la política. Compatibilizar todo es casi una "misión imposible", frente al uso del tiempo de los varones, libre de ataduras y reconocido en las estadísticas oficiales. Si el tiempo de trabajo no remunerado se realiza mayoritariamente en el hogar y su volumen se está comenzando a estimar tímidamente ${ }^{1} \mathrm{y}$ con bastantes limitaciones, a partir de encuestas y estudios; el tiempo de trabajo remunerado, que es el reconocido, se considera desde una amplia cobertura estadística. En este sentido, las mujeres españolas engrosan las listas de "población inactiva" ya que "no trabajan" por dedicarse a las labores del hogar travestidas bajo el título de "amor de casa"-y entenderse que no producen bienes o servicios para la comunidad-, frente al número de varones activos y ocupados que duplican al de mujeres.

Asimismo, buena parte de las mujeres "productivas" se ven obligadas a desertar del ámbito público laboral, al no poder compatibilizarlo con el trabajo doméstico cada vez más cargado por las nuevas circunstancias socio-culturales (incremento de la tercera y cuarta edad por inversión de la pirámide demográfica) y carecer de medios y recursos económicos y temporales. En estas circunstancias, pensar en promoción laboral de las mujeres es, entre otras razones, prácticamente quimérico en tanto que se ven abocadas a la renuncia profe-

1 Para subsanar dicha laguna, merecen destacarse los esfuerzos realizados por la Economía feminista. Entre los trabajos más recientes, véase Gálvez Muñoz, L. (dir.) (2016), La economía de los cuidados, Sevilla: Deculturas.

2 Las personas que se incluyen en el ítem de Población inactiva son aquéllas que no producen bienes o servicios para la comunidad. A esta categoría pertenecen pensionistas y personas jubiladas, las y los estudiantes, las personas con incapacidad permanente y las "amas de casa". La población activa es la población ocupada más la población parada, y se define como el conjunto de personas de una edad determinada (entre los 16 y los 65) que, en un período de referencia dado, suministran mano de obra para la producción de bienes y servicios económicos o que están disponibles y hacen gestiones para incorporarse a dicha producción. Se encuentran en este grupo aquellas personas que cuentan con un empleo o están en disposición de tenerlo, es decir, la población ocupada y la parada entre los 16 y los 65 años. 
sional, en mayor o menor medida, durante los años de "reproducción", y a ocuparse de la tareas pre-asignadas de atención y cuidado de los otros -menores, enfermos y ancianos en segundo grado de consanguinidad y/o afinidad-, ahora también por ley.

Las condiciones, pues, previas al desempeño de tareas profesionales no son las mismas entre hombres y mujeres. De hecho, la desigual distribución de las responsabilidades domésticas sigue constituyendo unas de las principales barreras microsociales que la mujer encuentra para ser activa en el mundo laboral, ya que dicha desigualdad determina que la mujer tenga una menor disponibilidad de la energía física, mental y afectiva para dedicar a su empleo y profesión, además de cierto grado de "desequilibrio" mental (ya conocemos los síndromes psiquiátricos de moda, porque no pasan: "la superwoman", "la abuela esclava"...). Y el empresario, y digo bien, en masculino, lo sabe: el 30\% de los hombres empresarios $^{3}$ prefiere contratar a un varón en su empresa, al tiempo que el 57,6\% piensa que existen perfiles profesionales más adecuados y propios de hombres y otros de mujeres. Quizás por esta razón, el 60\% de las mujeres que trabajan a tiempo parcial lo hacen, no por mor de la voluntas, sino porque no ha podido encontrar trabajo en jornada completa; y en segundo término, porque debe ocuparse del cuidado de personas dependientes (menores y/o personas adultas enfermas, incapacitadas, en segundo grado de consanguinidad y/o afinidad).

Y los datos vuelven a resultar reveladores: la diferencia de trabajo realizado por las mujeres en España, pero que no es reconocido porque no es remunerado -eso que gusta llamarse "labores del hogar o amor de casa"- se calcula en 91 días al año. Y la propia inercia nos incita a seguir sumando. Si a los 91 días de trabajo extra dentro del hogar, sumamos los 88 días que se calcula -según datos de la Encuesta Anual de Estructura Salarial- éstas trabajan de más que sus compañeros varones para conseguir cobrar lo mismo $(24 \%$ de brecha salarial), el resultado es un total de 179 días gratis de trabajo al año. Ciertamente, quien puede desaprovechar las ventajas de beneficiarse del "trabajo" de las mujeres -autoestimuladas además de ser, paradojas de la vida, el recurso humano más preparado hoy por hoy en España. Dicho esto, es de entender, pues, que éstas cobren casi un $40 \%$ menos de pensión que los hombres; y que engrosen las listas de pensiones no contributivas (el 70\% de quienes la reciben son mujeres). Es lo que tiene el seguir considerando trabajo aquel que se encuentra dentro del mercado productivo, directamente generador de bienes y servicios y empeñarse en no redefinirlo.

Pero llegado este punto, el siglo XXI debe afrontar el reto nada fácil de aparcar las palabras y ponerse a hacer para dejar de girar en torno a debates estériles sobre la igualdad efectiva ciudadana. Reflexionar sobre un modelo igualitario que permita conciliar la vida personal, profesional y familiar de las personas, implica reconocer el enorme y fructífero trabajo que las mujeres realizan dentro del hogar, con la consiguiente valoración en lo que

3 Frente al 30\% de los hombres empresarios que prefieren contratar a un varón en su empresa, al 75,5\% de las mujeres empresarias le es indiferente que sea hombre o mujer. El porcentaje que tiene preferencia $(24,5 \%)$ se reparte equitativamente entre la opción de trabajador o trabajadora. En cambio, los hombres empresarios que muestran neutralidad representan sólo el $69,5 \%$ del total y el 30\% restante, como decíamos al inicio, prefiere con exclusividad a un hombre para su empresa. Datos provenientes de un estudio elaborado por el Instituto Andaluz de la Mujer, el Centro de Estudios Andaluces y la Universidad de Málaga, 2017, realizado por Óscar Marcerano. Asimismo, no debe desconocerse la aportación y datos de la obra de Castaño, C. (dir.) (2015), Las mujeres en la gran recesión: políticas de austeridad, reformas estructurales y retrocesos en la Igualdad de Oportunidades, Valencia: Cátedra, Colección Feminismos. 
a consecución de bienestar se refiere; y significa tenerlo muy presente en el momento de arbitrar medidas institucionales, con el fin de no adjudicar -y legitimar- éstas y otras tareas nuevamente sobre las espaldas de las mujeres. De no hacerlo así, el Estado contribuirá al mantenimiento del sistema patriarcal; creará ilusiones ópticas de igualdad; asignará las funciones domésticas según sexo; y contribuirá, con su aportación institucional, a la generación y mantenimiento de la violencia estructural contra las mujeres: si las mujeres no participan es porque no quieren. Y es aquí donde el Estado se erige como gran maltratador. Un Estado que siga impulsando el trabajo solapado y silencioso de las mujeres en el hogar; que no reconozca el valor social de la maternidad; que no arbitre medidas institucionales de apoyo a la conciliación, mirando fijamente a los ojos de las mujeres; que siga sin intervenir en los procesos de socialización diferencial; que quiera cubrir objetivos sociales reduciendo como sea y a costa de quien sea el gasto público; que se legitime con una legislación aparentemente tuitiva e igualitaria; que potencie el abandono del desarrollo profesional de más de la mitad de la ciudadanía... no puede tacharse, en ningún caso, de Social y Democrático de Derecho, tal y como reza el artículo 1.1 de nuestra Constitución española. Y estos adjetivos son más que meras palabras que vienen a embellecer nuestro texto legal, sino que obligan de manera imperativa, y cuyo cambio -o apenas matización- generaría la modificación de la Ley de leyes según el mecanismo arbitrado por el art. 168 de la Constitución. De no activar medidas efectivas que permitan el desarrollo fáctico de la igualdad ${ }^{4}$ y la participación de la ciudadanía en la vida social, cultural, económica y política del pueblo (art. 9.2 de la Constitución), será el Estado quien aplique violencia contra las mujeres -por omisión-, no permitiendo el desarrollo pleno y libre de su autonomía personal. Y es que cuando hablamos de mujeres, hablamos de ciudadanía y la máxima laissez faire, laissez passer-mirando hacia otro lado-, aquí no vale.

\section{Punto de partida socio-laboral y crisis del Estado de bienestar: una lectura de género}

La conclusión parece harto evidente: la situación de las mujeres en el empleo deriva de su papel en el ámbito familiar que les impide disponer del tiempo y dedicación que requiere el desarrollo de una profesión o de un trabajo o de un proyecto autónomo, al tiempo que la dedicación que los hombres emplean en trabajo remunerado determina, en parte, el tiempo que tienen para sus familias o para el trabajo reproductivo. Y los datos vuelven a resultar reveladores: las mujeres españolas dedican 7 horas y 35 minutos al trabajo doméstico frente a las 3 horas y 5 minutos empleadas por los varones. Si es verdad que parece difícil reducir la barrera de 4 horas diarias de trabajo doméstico por persona, sin que ello implique derivar el trabajo hacia los servicios monetarizados o hacia otras personas, el excedente de trabajo femenino configura una masa de trabajo enorme equivalente a la de todo el tiempo diario asalariado. Esta realidad condiciona y certifica "la especialización femenina" en el trabajo doméstico $-80,5 \%$ del volumen total de horas dedicadas a esta actividad- frente al trabajo

4 Tamar Pitch se refiere a la necesidad de "tomar en serio las experiencias de las "mujeres" y partir de las mismas bien para hacerlas visibles al Derecho, bien para crear derechos a su medida", en Pitch, T. (2003), Un Derecho para dos. La construcción jurídica de género, sexo y sexualidad, Madrid: Trotta, p. 259. 
extradoméstico donde tiene, sin duda, una menor penetración, apenas un 26,8\%. ¿Quién podría poner en duda, con estos datos en la mano, la legitimidad y la urgencia de las necesarias medidas de acción positiva diferenciadora y la necesidad y urgencia de intervención estatal que apueste por una red de servicios sociales solventes?

Ante esto, hago mías las palabras que Berit Äss publicara hace ya casi treinta años, aún de suma actualidad: “(r)etener información es algo muy grave. En Suecia se han calculado que en nuestros días, las mujeres realizan nueve mil millones de horas de trabajo al año, y los hombres seis mil trescientos millones de horas. Cuando la sociedad masculina nos pregunta: ¿por qué no competís con nosotros en los sindicatos, en los lugares de trabajo, en los partidos?, deberíamos contestar: Hay una cierta cantidad de trabajo extra que nosotras no hemos pedido. Siempre nos ofrecéis que compitamos basándonos en vuestras premisas y estáis reteniendo información"5.

Esta situación "emancipatoria" para las mujeres se manifiesta, pues, y ante todo, con una carencia de tiempo de vida6: tiempo para el ocio, para la formación y el reciclaje, para la participación social y política, para el desarrollo personal, para la promoción profesional... Y el uso del tiempo es algo más que un tema puntual de reflexión. El uso del tiempo implica una forma de vida, en tanto que la vida, en definitiva, no es más que tiempo. Y si se adjudica a las mujeres un tiempo de vida hipotecado, habrá que admitir que ésta no hará un uso libre y legítimo de su voluntad para dirigir y disfrutar ésta, sino que dependerá de las necesidades reproductivas (no remuneradas) que volquemos sobre ellas. No olvidemos que los grandes productores son a su vez grandes consumidores de necesidades sociales que alguien debe cubrir; y esto tiene un coste.

Los indicadores de igualdad evidencian, con carácter general, que la posición social de los hombres es casi cuatro veces mejor que la de la mujer, en atención al uso que hacen de su tiempo. De hecho, el porcentaje de horas semanales en días laborables dedicadas al trabajo doméstico según sexo y rol familiar, en el estrato de más de 20 a 30 horas, se eleva a 21,4 en la variable madre, frente al tímido 4,7 en la variable padre, 14,9 en la de hija y un exiguo 3 en la de hijo. En los días festivos, el porcentaje de horas dedicadas al trabajo doméstico no parece alterar el grado de co-participación de los distintos miembros familiares. A saber: en el mismo estrato de 20 a 30 horas, se eleva a 12,9 en la variable madre, frente a un ridículo 0,8 en la variable padre; 1,8 en la de hija y un 1,2 en la de hijo. La calidad de vida, índice medido a través del uso del tiempo, indica, pues, un nivel, en las mujeres $(28,35)$, tres veces inferior al de los hombres. Y con respecto al grado de autonomía, esto es, a la capacidad de decisión en la distribución de su tiempo, su valor es de 32,20 en las mujeres. El grado de autonomía de las mujeres es tres veces menor que el de los hombres.

5 Berit Äs (1990), «El papel político de la mujer», en: J. Astelarra (comp.): Participación política de las mujeres, Madrid: CSIC y Siglo XXI, p. 206.

6 Según el Estudio de la Fundación Pfeizer "Conciliación y familia", 2014, realizado sobre 1500 entrevistas a mayores de 16 años de todo el territorio nacional, un tercio de la población activa española afirma que tiene problemas para conciliar su vida laboral y personal, sobre todo por la incompatibilidad de los horarios (24\%), por el hecho de pasar demasiadas horas en el trabajo $(16,8 \%)$, lo que se traduce en falta de tiempo para estar con la familia (17\%) o la ausencia de ocio (16\%). Este informe es accesible en la web www.fundacionpfizer.org. 
Ante este panorama, pueden entenderse perfectamente los últimos datos ofrecidos por la experticia en Psicología y Psiquiatría ${ }^{7}$. Las mujeres padecen de depresiones ${ }^{8}$, no diagnosticadas muchas de ellas, ocasionadas por el estrés que implica el tener que compatibilizar todas las tareas productivas y reproductivas y que afectan especialmente a las comprendidas en la edad de 35 a 50 años ${ }^{9}$. En paralelo, las abuelas ${ }^{10}$ han adquirido el rol imprescindible de cuidado y atención de los nietos. El síndrome de la superwoman ${ }^{11}$, y el de la abuela esclava, síndromes que han pasado a formar parte de los anales de la psiquiatría -pero que no pasan de moda-, avanzan posiciones en una sociedad que se califica de democrática, igualitaria y de bienestar.

Todo este panorama obliga a que las relaciones entre el mundo laboral, la esfera doméstica, el Estado y las necesidades sociales, sean transformadas. Y ello es así porque de su superación depende tanto la reproducción social, como el logro de la igualdad material ciudadana.

Pero, quizás, el quid de la cuestión radica en la exclusión de las mujeres del modelo de ciudadanía construido por y para el hombre en la Modernidad; y la no recuperación, en la actualidad, de ciertos aspectos emancipadores que podían haber resignificado el concepto, dotándolo de cierta legitimidad. El no hacer mención expresa de la situación de subordinación estructural ${ }^{12}$ que arrastran desde siempre las mujeres impulsa un modelo

7 Entre las investigaciones más recientes, y que vienen a confirmar que: "La mayor incidencia de la depresión en las mujeres no debe buscarse en la biología, en su fisiología, en su cuerpo, sino en las condiciones de vida y en las características de su subjetividad”. Dio Bleichmar, E. (1992), La depresión en la mujer, Madrid: Ed. Temas de Hoy; véase Zarragotía Alonso, I. (2013), «Las diferencias de sexo y género en la depresión: proclividad en la mujer», Medwave, 13(3):e5651 doi: 10.5867/medwave.2013.03.5651. Véase también Monteso Curto, M.P. (2015), La depresión en las mujeres. Una visión multidisciplinar desde la perspectiva de género, Tarragona: Publicacions Universidad Rovira Virgili.

8 Según la OMS existen 400 millones de personas que sufren alguna clase de depresión en el mundo (4 millones en España). De la totalidad, 20\% se concentran en las llamadas depresiones endógenas, y el $80 \%$ restante, a razones exógenas. De este último grupo, el $70 \%$ es padecido por las mujeres (1.600.000 depresiones exógenas femeninas en España), lo que apunta a lo que se ha denominado "depresión de género", cuyas causas no son biológicas, genéticas ni hereditarias, sino propias de la situación de subordinación estructural que padecen las mujeres. Datos consultables en www.mujeresparalasalud.org/spip.php?article55

9 El Estudio Somos un equipo de la Asociación Yo no renuncio, de 2017 antes referido en torno a la corresponsabilidad en las familias españolas destaca que al agrupar las tareas según la actividad, el 48,3\% de las mujeres comenta que es la principal responsable de las labores domésticas (10,5\% de los hombres), el 48,9\% de la alimentación (frente al 12,9\%), y el 50,5\% del cuidado de la prole (5,5\% en el caso del hombre). La mujer también lidera, en un 54\%, la responsabilidad de las tareas invisibles y organizativas, tales como la planificación y seguimiento médico y escolar de lo/as niño/as, frente al 17\% de los varones. El informe se inclina a valorar que aunque se haya podido detectar una ligera implicación de los hombres en las labores del hogar, no parece seguirse el mismo proceso evolutivo en la mejora de las condiciones laborales para las mujeres.

10 Según el Estudio de la Fundación Pfizer "Conciliación y familia", 2014, un tercio de la población española encuestada, dice estar ayudando a familiares o personas de su entorno cercano afectados por la crisis, ofreciéndoles dinero, comida y apoyo. Las abuelas se encuentran dedicadas en su mayoría (59,3\%) al cuidado y atención de los nietos. Asimismo tampoco puede desconocerse su imprescindible colaboración económica a la familia. El 33,3\% lo hacen. Este informe es accesible en la web www.fundacionpfizer.org

11 Las demandas y quejas de las mujeres hacia el supuesto nuevo orden emancipatorio, libertador entre los sexos, y las consecuencias psico-físicas que la doble y triple jornada estaba ocasionando en la población femenina, ya fueron puestas de manifiesto desde hace más de tres décadas por numerosas autoras. Un ejemplo de ello es la obra de Fitoussi, M. (1990), Le Ras-le-bol des superwomen, Paris: Calmann-Lévy.

$12 \mathrm{Al}$ respecto y centrado en la brecha salarial, véase Cabeza Pereiro, J. (2012), «La discriminación retributiva por razón de sexo como paradigma de discriminación sistémica», Lan Harremanak/Revista de Relaciones Laborales, $\mathrm{n}^{\circ} 25$. 
de ciudadanía ${ }^{13}$ excluyente y exclusivo de los varones. Hablar pues de igualdad, requiere, apostar por un nuevo Pacto Social ${ }^{14}$ que incluya esta vez a todas y a todos, ofreciendo una protección estatal, esta vez sí, a toda la ciudadanía.

Esta conclusión proveniente de nuestra primera tarea -análisis de la situación sociolaboral de las mujeres- recupera otro frente que tendremos que combatir si es que pretendemos arribar a la igualdad real que no sólo formal. Se requiere una catarsis estructural e institucional -activando los principios ya conocidos de antidiscriminación y antisubordinación-, enfocada siempre hacia un cambio de modelo. Urge romper con la ecuación Mujer=Esposa=Madre=Hija, trabajar la subjetividad, los modelos simbólicos, impulsar la corresponsabilidad de las responsabilidades domésticas entre sexos y abordar seriamente el fenómeno de la desigualdad o discriminación estructural aparejado a la división de las esferas mercado-familia. De no ser así, las tareas domésticas se derivarían al trabajo monetarizado (asistenta) o no (abuela) identificado con rostro de mujer, las mujeres persistirían en no tener descendencia, los hijos e hijas sufrirían las consecuencias reales de no tener tiempo (ni renta) para ellos, y como no, continuaríamos con un modelo de ciudadanía falsamente universalista y elitista, reservado a los de siempre: varones, blancos, adultos y propietarios.

Lamentablemente las medidas jurídico-políticas adoptadas, especialmente durante estos años de crisis, no han ayudado, sino todo lo contrario, a conseguir mayores niveles de igualdad fáctica ciudadana. No en vano, las mujeres en España se han visto particularmente afectadas por la política de austeridad que ha recaído, muy especialmente, en recortes del sector público, en tanto que representan el $70 \%$ de la mano de obra en el sector. Asimismo, los recortes en la atención pública y los servicios de salud favorecen el retorno a los roles tradicionales de género. A nivel mundial, tal y como indica el Informe Global de la Brecha de Género publicado por el Foro Económico Mundial el 25 de octubre de 2016, serán necesarios 170 años (52 años más) para cerrar la brecha económica de género en el mundo -frente a los 118 años previstos en 2015.

Se requiere una red de servicios sociales solventes -también en nuestro sistema de Seguridad Social- para restringir las prácticas más informales de cuidado de las personas; se requiere apostar por la maternidad promoviendo y reconociendo el importante valor de la misma; se requiere una normativa laboral y no sólo laboral (no proteccionista, sino promotora) que reconozca a las mujeres como ciudadanas y no como "colectivo atípico" que demanda soluciones parcheadas... En definitiva, se reclama el enfoque transversal institucional que incorpore la perspectiva de género de manera principal (gender mainstreaming) y que destine sus recursos -humanos y económicos- a conseguir el objetivo último ratificado que es la igualdad efectiva ciudadana.

Pasemos a analizar desde una perspectiva de género algunas de las medidas arbitradas en tres ámbitos de intervención -desempleo y pobreza, trabajo de cuidados y violencia de género- $\mathrm{y}$ a desvelar el alarmante estado de desprotección de las mujeres, en tanto que ciudadanas, por parte del Estado español.

13 A nivel comunitario, $\mathrm{M}^{\mathrm{a}}$ Ángeles Barrère ya lamentó la oportunidad perdida de refundar el concepto de ciudadanía europea tanto por el Tratado de Maastricht de 1992 como por las modificaciones introducidas en Ámsterdam e insiste en la importancia de elaborar un concepto europeo de ciudadanía basado en la igualdad de género. Véase Barrère Unzueta, M.A (2003), «Ciudadanía europea e igualdad de género», Revista Vasca de Administración Pública, $\mathrm{n}^{\circ}$ 66, pp. 47-66.

14 Al respecto, la referencia al trabajo de Carole Pateman es obligada. Pateman, C. (1988), The Sexual Contract, Cambridge; Policy Press. Existe traducción al castellano (1995), El Contrato Sexual, Barcelona: Anthropos. 


\section{La respuesta española ante la crisis y la desprotección de las mujeres como ciudadanas}

Recientemente, en febrero de 2015, el Comité Europeo de Derechos Sociales (CEDS) ha llamado la atención al Estado español por la disconformidad de la legislación interna laboral con los preceptos reconocidos en la Carta Social Europea (centrada en lo socio-laboral), durante el período de 1 de enero de 2009 a 31 de diciembre de 2012. La prueba de este corte transversal de la estructura sexo-género lo encontramos, por ejemplo, en las recientes medidas de reforma laboral adoptadas por el Gobierno (Real Decreto-Ley 3/2012, de 10 de febrero), y convalidadas por el Tribunal Constitucional que, sin duda, repercuten duramente sobre las mujeres. Y es que el aumento de la tasa de pérdida (y/o precarización) de empleo femenino ha supuesto menor atractivo a su contratación; importantes recortes presupuestarios del sector público (como seguidamente constataremos); la Reforma de la Administración Local; y la consecuente intensificación por parte de las mujeres de tiempos y trabajos no remunerados en el seno del hogar (especialmente de las mujeres con rentas más bajas). Pese a la superación del trámite constitucional, esta reforma no supera el control de convencionalidad según el CEDS (Conclusiones XX-3 de 2014). Asimismo, el Comité Europeo refiere siete conclusiones de no conformidad con la Carta Social Europea que merecen ser mencionadas y observadas con la lupa metodológica del género.

Dichas conclusiones se refieren a: la insuficiencia del salario mínimo profesional, la flexibilidad de tiempo de trabajo, la compensación de las horas extraordinarias, las medidas compensatorias para personas trabajadoras expuestas a riesgos residuales para su salud, el período razonable de preaviso para la terminación del contrato (incluido el período de prueba en el contrato de apoyo a los emprendedores), la inaplicación unilateral del convenio colectivo, la injerencia del Gobierno en el ejercicio del derecho de huelga, a través del arbitraje obligatorio y la criminalización de la participación en huelgas.

Ya con anterioridad, el Comité Europeo de Derechos Sociales había señalado incumplimientos del Estado español (Conclusiones XX-2 (2013) en relación a los derechos del ámbito de la salud y la protección social (art. 3,11, 12, 13, 14 de la CSE y art. 4 del Protocolo) con claras repercusiones de género, habida cuenta de la importante ratio de mujeres inmigrantes irregulares en nuestro país y de las dificultades de las mujeres para encontrar trabajo. En ellas se declaraba la disconformidad con la Carta Social Europea de las normas internas por las que se excluía del Sistema Nacional de Salud a las personas extranjeras por razón de su estatus irregular. Esta discriminación deriva del $R D$ 16/2012, de 20 de abril, de medidas urgentes para garantizar la sostenibilidad del Sistema Nacional de Salud y mejorar la calidad y seguridad de sus prestaciones y de la Ley 16/2003, de 28 de mayo, de cohesión de calidad del Sistema Nacional de Salud, y el RD 12/2012, que requería para estar asegurado la residencia legal en España, lo que implicaría la exclusión de facto de la asistencia sanitaria de las personas extranjeras en situación irregular, pero también excluía a las personas de nacionalidad española de 25 años sin cotizaciones previas, la mayoría mujeres. Tampoco podemos olvidarnos de la especial vulnerabilidad de las mujeres inmigrantes -sin papeles- que, en el mejor de los casos, se dedican a empleadas de hogar y/o cuidado de personas dependientes, o a la prostitución o víctimas de mafias de trata de seres humanos.

El Comité Europeo de Derechos Sociales desecha en su último informe el argumento de la crisis como justificativo de restricciones legales en derechos sociales incluidos en la Carta Social Europea y que, por el contrario, deben ser especialmente garantizados en estos momentos. 
Sin embargo, un inevitable análisis con perspectiva de género a los actuales Presupuestos Generales del Estado de 2016 nos permitirá concluir el abandono de la protección de los derechos de las mujeres como ciudadanas. Partamos de tres áreas de intervención, propias de los tres principales objetivos que se deben alcanzar según el Pacto Europeo por la Igualdad de Género (2011-2020), en el contexto de la Estrategia 2020, a saber: reducir las desigualdades en cuanto a empleo y protección social, promover un mejor equilibrio entre la vida laboral y privada de mujeres y hombres y combatir todas las formas de violencia contra las mujeres.

\subsection{Desempleo y pobreza}

El Estado español, en estos años de crisis global, ha apostado por una política de recortes que, sin duda, repercute desde un análisis de género, directamente sobre las mujere ${ }^{15}$ como ciudadanas. Algunas de estas medidas son: la incentivación de la contratación a tiempo parcial (modificando el régimen de las horas complementarias, para flexibilizarlo, o suprimiendo la preferencia de acceso a un puesto a tiempo completo), la congelación (o nula subida) del salario mínimo interprofesional, o los recortes en la Protección de desempleo: RAI, desvirtuándose el carácter asistencial de esta prestación, o el aplazamiento sine die de una mejora sustantiva de la pensión de viudedad. En este sentido, la reducción de un $22 \%$ de la partida de prestaciones ahondará la ya existente brecha de género $(22,55 \%$ o trabajar 82 días más al año que el varón y ser diplomada universitaria), habida cuenta de que las mujeres cuadruplican su presencia en trabajos a tiempo parcial y de corta temporalidad. Son empleos con pobreza e implican a su vez parcialidad salarial, de promoción profesional y de prestaciones sociales incluidas las de jubilación. En estos últimos cuatro años (2012-2015) la brecha entre la Tasa de paro de mujeres y hombres se ha triplicado. Asimismo, resulta obligado insistir en la omisión del análisis de género en los ingresos y Seguridad Social, cuando las pensiones contributivas y no contributivas vuelven a subir en 2016 , el $0,5 \%$, y las pensiones de viudedad están en el centro del debate, siendo las mujeres el 93\% de los 2,3 millones de personas que viven de ellas. En la actualidad, y tras estos años de crisis ${ }^{16}$ y austericidio, la situación de las mujeres pensionistas se presenta peor y con mayor brecha de género que la existente en 2008.

Todo apunta a la necesidad de revisar el sistema de Seguridad Social, diseñado en su origen, en concordancia con el modelo laboral masculino, en donde el sustentador es el varón trabajador versus la esposa dependiente (que no sujeto), objeto de los derechos derivados. Las reglas del sistema retroalimentan esta desigualdad y empuja a las mujeres a la precariedad durante su vida laboral y a la dependencia económica durante el resto de su vida.

Asimismo, se ha reducido la financiación a los ayuntamientos -Ley 27/2013 de reforma de la Ley de Régimen Local- que deja sin recursos a los servicios sociales base, lo que

15 En este sentido, véase también Ballester Pastor, M.A. (2015), «Desigualdad y mujer tras la crisis», Anuario de Relaciones Laborales en España, ${ }^{\circ}$ 6, pp. 181-183.

$16 \mathrm{Al}$ iniciarse la crisis, entre las pensiones medias de uno y otro sexo había una diferencia del $28,7 \%$, manteniéndose prácticamente hasta 2011. En los dos años siguientes, inmersos en ella, la brecha se abrió abruptamente elevándose al 29,6\% en 2012 y al 32,6\% en 2013. En la actualidad, pese a la leve recuperación, no ha sido posible compensar el decalage entre pensiones. Datos recogidos recientemente por Vicente Clavero en su artículo "Desigualdad. La brecha entre las pensiones de hombres y mujeres se ha ensanchado durante la crisis", Público, 8 de febrero de 2017. 
desde una visión de género alerta del abandono de las mujeres y de su prole a la más absoluta pobreza. Es lo que se ha venido llamando feminización de la pobreza. Como muestra, un botón: el $72 \%$ de las personas beneficias del programa de solidaridad para personas con riesgo de exclusión social de la Junta de Andalucía, son mujeres.

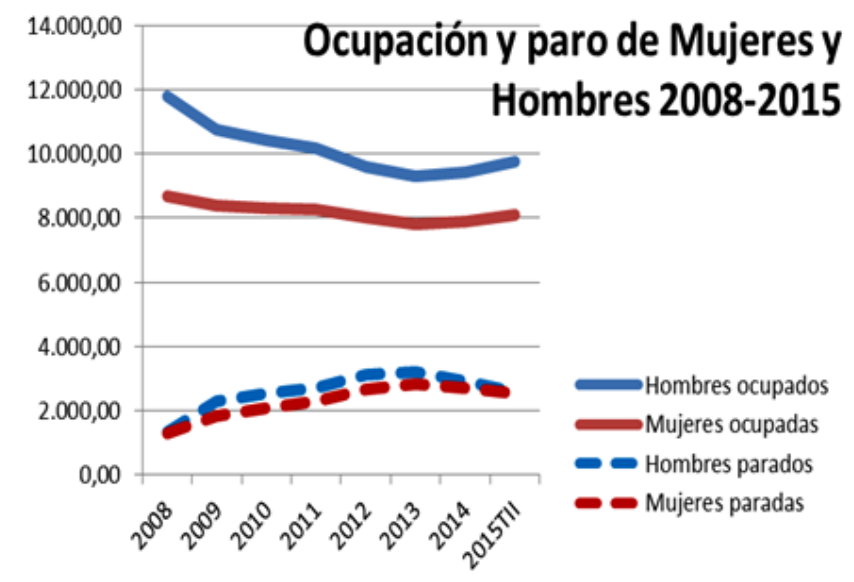

Fuente: Manifiesto Feminista sobre los Presupuestos Generales del Estado para 2016.

\subsection{Trabajo de cuidados y conciliación}

El trabajo reproductivo (sin remuneración ni reconocimiento) sigue estando en manos de las mujeres lo que repercute, ineludiblemente, en las condiciones laborales, nivel de ocupación y tipo de empleo. Si a ello le sumamos la suspensión de la ampliación del permiso de paternidad hasta enero de 2017, la falta de dotación de escuelas infantiles de 0 a 3 años o la nimia subida en dependencia, destinada a disolverla (dentro y fuera de los domicilios), ineludiblemente el empuje y destierro de las mujeres al hogar es inevitable. En 2014 se tramitaron 31.435 excedencias por cuidado de hijo/as, de las cuales el $94 \%$ fueron tomadas por mujeres, porcentajes que se ha mantenido en 2015 (92\%). No olvidemos tampoco que el $97 \%$ de las personas que cuidan a personas dependientes son mujeres -tanto en el caso de las auxiliares de las residencias, como mujeres que se ocupan de ello dentro del hogar- y que 500.000 personas perdieron la ayuda a domicilio.

$\mathrm{Si}$ a ello le sumamos que España sólo destina a las familias el 1,31\% del PIB, frente al 2,2\% de media europea ${ }^{17}$, y que las prestaciones familiares españolas apenas suponen el 59\% de la comunitaria, entenderemos la falta de compromiso político y la dejación de responsabilidades reproductivas en las espaldas de las mujeres.

17 Frente a España y superando la media europea, nos encontramos con países con una inversión significativa del PIB en las familias; a saber: Dinamarca invierte el 4,1\% del PIB, Luxemburgo el 3,6\% e Irlanda el 3,4\%, lo que repercute en un aumento de la natalidad y en la consecuente mejora de la calidad de vida de los miembros que conforman la unidad familiar. 


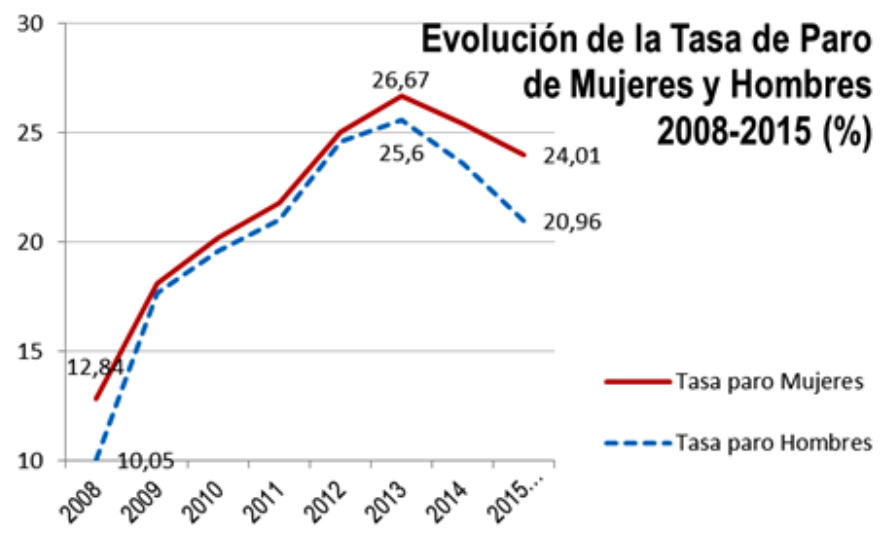

Fuente: Manifiesto Feminista sobre los Presupuestos Generales del Estado para 2016.

Y es que las últimas modificaciones acometidas por la Reforma Laboral ${ }^{18}$ de 2010 y 2012 han considerado el derecho a la conciliación como un espacio más, susceptible de recortes flexibilizadores unidireccionales (en interés de la empresa) y no como un ámbito que requiere especial protección ${ }^{19}$, tal y como exige la Ley de Igualdad y la normativa comunitaria. Algunos ejemplos de esta política de "reprivatización de la reproducción social"20 son: el cambio en el alcance del derecho subjetivo a la lactancia; la reformulación del alcance de las reducciones de jornada ${ }^{21}$ por cuidado de menores o familiares (cómputo diario), el debilitamiento de la negociación colectiva y el empoderamiento de los criterios establecidos por Convenio Colectivo para la concreción horaria de la reducción de jornada por cuidado (art. 37.6 E.T.) y la distribución irregular del 10\% de la jornada de trabajo (art.34 E.T), la desaparición de las bonificaciones establecidas en el art. 4.2 de la Ley 43/2006, para facilitar la reincorporación de la mujer trabajadora tras la maternidad o la excedencia por cuidado de hija/os o las modificaciones en la movilidad geográfica (art. 40 E.T.) y modificación sustancial de condiciones de trabajo (art. 41 E.T.) ${ }^{22}$.

18 Esta gran Reforma se ha instrumentalizado a través del Real Decreto Ley 10/2010, de 16 de junio, de medidas urgentes para la reforma del mercado de trabajo, de la Ley 35/2010, de 17 de septiembre, de igual título, del Real Decreto Ley 3/2012, de 10 de febrero, de medidas urgentes para la reforma del mercado laboral y de la Ley 3/2012, de 6 de julio, de igual título.

19 Al respecto, merece la pena la lectura de Ballester Pastor, M.A. (2012), «De cómo la reforma operada por el Real Decreto Ley 3/2012 ha degradado el derecho fundamental a la conciliación de responsabilidades», Revista de Derecho Social, $\mathrm{n}^{\circ}$ 57, pp. 99-100.

$20 \mathrm{Al}$ respecto, véanse las siempre interesantes aportaciones de Lousada Arochena, J.F. (2013), «La reforma laboral en perspectiva de género», recogidas en el XIV Congreso Nacional de Abogados Laboralistas, organizado por la Asociación Nacional de Abogados Laboralistas, A Coruña, 26/10/2013.

21 Véase el artículo de Pazos Pérez, A. (2012), «La reducción de jornada tras las últimas reformas legislativas», en: M. Fernández Prieto y J. Cabeza Pereiro (ed.): Políticas de conciliación, permisos parentales y empleo, Albacete: Bomarzo, pp. 242 y ss.

22 Para un desarrollo y reflexiones en torno a esta "reprivatización de la reproducción social", permítanme remitir a mi trabajo Gil Ruiz, J.M. (2017), «Crisis del Estado de Bienestar y desafíos del siglo XXI: dualismo vital y brecha ciudadana», Revista Vasca de Administraciones Públicas (en prensa), o a las aportaciones de Ballester Pastor, M.A. (2013), «La flexibilidad interna o el fortalecimiento del ius variandi empresarial en el contexto: 


\subsection{Violencia de género en el contexto de pareja}

Los Presupuestos Generales del Estado han aumentado en un 6,3\% los recursos destinados a violencia de género en el contexto de pareja, pero siguen estando por debajo de los niveles de 2009 (baja el 10,92\%), resultando claramente insuficientes para afrontar esta lacra social. Con la crisis, en apenas tres años, se han reducido en $30 \%$ los fondos para prevenir la Violencia. Ya en 2015 se pretendió corregir la cifra incrementando un 8.6\% estas partidas (aumentando la partida de Igualdad Efectiva a 20,82 millones y 23,7 millones la de Violencia de Género), pero esto supone, en conjunto el $0,01 \%$ del presupuesto total, además de ser una cantidad insuficiente para suplir el recorte de los Ayuntamientos antes referido. Esto ha supuesto el cierre de casas de acogida, Centros de la Mujer y la destrucción de 5.000 puestos de trabajo23.

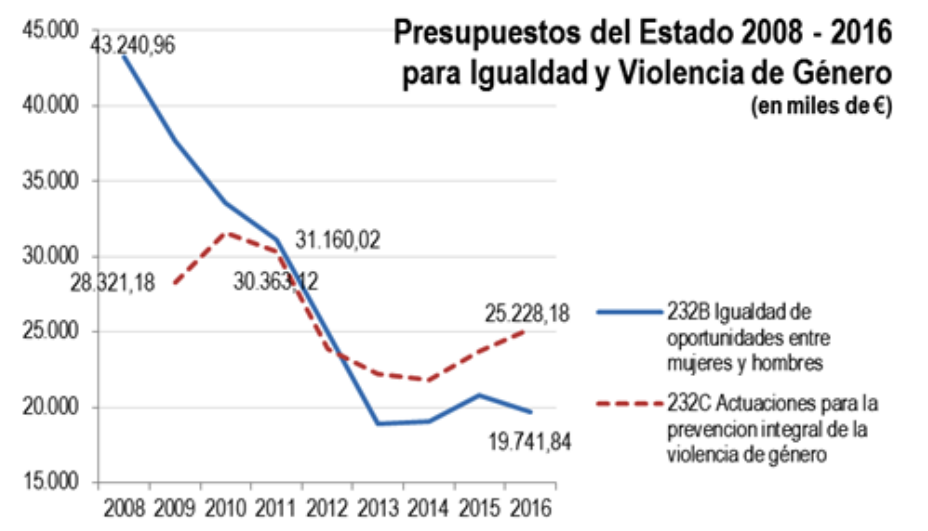

Fuente: Manifiesto Feminista sobre los Presupuestos Generales del Estado para 2016.

Por supuesto, mucho hay que decir sobre la escasez de recursos para formación en género, exclusión en los curricula de asignaturas formativas ${ }^{24}$ al respecto, y centralización del enfoque de la violencia en el plano penal (aun deficitaria) en detrimento de la igualdad y del consecuente recorte en medidas educativas, preventivas y sociales. Un dato más de la confluencia de factores discriminatorios en las mujeres lo constata además el nada desdeñable incremento de la violencia de un $33 \%$ en las mujeres con discapacidad.

los defectos del modelo», Revista General de Derecho del Trabajo y de la Seguridad Social, $\mathrm{n}^{\circ} 34$. Algunos de estos desajustes -incluso anteriores a las reformas laborales restrictivas- los anuncié en Gil Ruiz, J.M. (2007), Los diferentes rostros de la Violencia de Género, Madrid: Dykinson.

23 Al respecto, véase Gil Ruiz, J.M. (2014), «La Violencia Institucional de Género», Anales de la Cátedra Francisco Suárez, nº 48, p. 11.

24 Esta exclusión en los curricula de asignaturas formativas en género, así como la necesidad y urgencia de incorporarlas de manera contrastada, ha sido ampliamente referida y denunciada en algunos de mis trabajos a los que me permito dirigir. Véanse Gil Ruiz, J.M. (2014), «Introducción de la perspectiva de género en las Titulaciones Jurídicas: hacia una formación reglada», Revista de Educación y Derecho. Education and Law Review, vol. 10; Gil Ruiz, J.M. (2015), «Formación en Derecho Antidiscriminatorio: carencias e incumplimientos institucionales», Revista ACADEMIA, vol. 26. pp. 49-77. 


\section{A modo de conclusión}

Este breve repaso por la situación socio-laboral de las mujeres viene a confirmar la situación penalizada de éstas como ciudadanas y el abandono de un Estado, que se hace llamar social y democrático de Derecho, pero que por mor de argumentos de austeridad ha vuelto a posponer -y a cargar sobre las espaldas de éstas- el reto de la consecución de la igualdad material ciudadana.

Es cierto que el paso del siglo XX al XXI ha supuesto la apuesta jurídica -tanto a nivel internacional como europeo- de un nuevo marco de trabajo ${ }^{25}$ y se ha detectado -aunque a veces, de manera bipolar- una evolución y construcción de lo que se ha venido a llamar un nuevo orden antidiscriminatorio ${ }^{26}$. No obstante, apenas si hemos empezado lo que se plantea como el auténtico reto del nuevo siglo, que sin duda requiere de una apuesta por un nuevo modelo ciudadano que supere la plantilla del varón (blanco, adulto y propietario), y un reconocimiento de las mujeres, retravesadas por los distintos cortes sistémicos, con sus especiales reivindicaciones e intereses propios a su sexo y humanidad. Ello implica enfocar las nuevas medidas hacia el objetivo de restaurar a las mujeres en su estatuto de ciudadanía, sin perder de vista tres ejes centrales de esta violencia estructural: los modos en que mujeres y hombres son socializados, el plus valorativo que tienen las actividades consideradas masculinas y la falta de reconocimiento de autoridad a las mujeres. En este sentido, no sólo se necesita ser un sujeto formal de derechos, sino que el otro con el que interactúo me considere un igual y no valore ni desmerezca mis derechos como una mera concesión, ahora obligada por el Derecho.

\section{Referencias}

Ballester Pastor, M.A. (2012): «De cómo la reforma operada por el Real Decreto Ley 3/2012 ha degradado el derecho fundamental a la conciliación de responsabilidades», Revista de Derecho Social, ${ }^{\circ}$ 57, pp. 99 y ss.

Ballester Pastor, M. A. (2013): «La flexibilidad interna o el fortalecimiento del ius variandi empresarial en el contexto: los defectos del modelo», Revista General de Derecho del Trabajo y de la Seguridad Social, $\mathrm{n}^{\circ} 34$.

Ballester Pastor, M. A. (2015): «Desigualdad y mujer tras la crisis», Anuario de Relaciones Laborales en España, $\mathrm{n}^{\circ}$ 6, pp. 181-183.

Barrère Unzueta, M. Á. (2003): «Ciudadanía europea e igualdad de género», Revista Vasca de Administración Pública, $\mathrm{n}^{\circ}$ 66, pp. 47-66.

Barrère Unzueta, M. Á. (2014): El Derecho Antidiscriminatorio y sus límites, Perú, Grijley. Berit Äs (1990): «El papel político de la mujer», en: J. Astelarra (comp.), Participación política de las mujeres, Madrid, CSIC y Siglo XXI, pp. 206 y ss.

Cabeza Pereiro, J. (2012): «La discriminación retributiva por razón de sexo como paradigma de discriminación sistémica», Lan Harremanak/Revista de Relaciones Laborales, $\mathrm{n}^{\mathrm{o}} 25$.

$25 \mathrm{Al}$ respecto, remito a Gil Ruiz, J.M. (2012), Las nuevas Técnicas Legislativas en España, Valencia: Tirant lo Blanch; Gil Ruiz, J.M. (2017), «En torno al artículo 14 de la CEDH: concepto, jurisprudencia y nuevos desafíos de (y ante) el Consejo de Europa», Revista Quaestio Iuris, vol. 10, nº 02, pp. 919-954.

26 Al respecto, véase Barrère Unzueta, M. (2014), El Derecho Antidiscriminatorio y sus límites, Perú: Grijley. 
Castaño, C. (dir.) (2015): Las mujeres en la gran recesión: políticas de austeridad, reformas estructurales y retrocesos en la Igualdad de Oportunidades, Valencia, Cátedra.

Dio Bleichmar, E. (1992): La depresión en la mujer, Madrid, Temas de Hoy.

Fernández Prieto, M. y Cabeza Pereiro, J. (ed.) (2012): Políticas de conciliación, permisos parentales y empleo, Bomarzo, Albacete.

Fitoussi, M. (1990): Le Ras-le-bol des superwomen, Paris, Calmann-Lévy.

Gálvez Muñoz, L. (dir.) (2016): La economía de los cuidados, Sevilla, deculturas.

Gil Ruiz, J. M. (2007): Los diferentes rostros de la Violencia de Género, Madrid, Dykinson.

Gil Ruiz, J. M. (2012): Las nuevas Técnicas Legislativas en España, Valencia, Tirant lo Blanch.

Gil Ruiz, J. M. (2014): «La Violencia Institucional de Género», Anales de la Cátedra Francisco Suárez, n 48, pp. 9-18.

Gil Ruiz, J. M. (2014): «Introducción de la perspectiva de género en las Titulaciones Jurídicas: hacia una formación reglada», Revista de Educación y Derecho. Education and Law Review, vol. 10.

Gil Ruiz, J. M. (2015): «Formación en Derecho Antidiscriminatorio: carencias e incumplimientos institucionales», Revista ACADEMIA, vol. 26, pp. 49-77.

Gil Ruiz, J. M. (2017): «En torno al artículo 14 de la CEDH: concepto, jurisprudencia y nuevos desafíos de (y ante) el Consejo de Europa», Revista Quaestio Iuris, vol. 10, $\mathrm{n}^{\circ}$ 02, pp. 919-954.

Gil Ruiz, J. M. (2017): «Crisis del Estado de Bienestar y desafíos del siglo XXI: dualismo vital y brecha ciudadana», Revista Vasca de Administraciones Públicas (en prensa).

Lousada Arochena, J. F. (2013): «La reforma laboral en perspectiva de género», XIV Congreso Nacional de Abogados Laboralistas, organizado por la Asociación Nacional de Abogados Laboralistas, A Coruña.

Montesó Curto, P. (2015): La depresión en las mujeres. Una visión multidisciplinar desde la perspectiva de género, Tarragona, Publicacions Universidad Rovira Virgili.

Pateman, C. (1988): The Sexual Contract, Cambridge, Policy Press. Existe traducción al castellano (1995): El Contrato Sexual, Barcelona, Anthropos.

Pazos Pérez, A. (2012): «La reducción de jornada tras las últimas reformas legislativas», en: M. Fernández Prieto y J. Cabeza Pereiro (eds.), Políticas de conciliación, permisos parentales y empleo, Albacete, Bomarzo, pp. 223-244.

Pitch, T. (2003): Un Derecho para dos. La construcción jurídica de género, sexo y sexualidad, Madrid, Trotta.

Zarragotía Alonso, I. (2013): «Las diferencias de sexo y género en la depresión: proclividad en la mujer», Medwave, 13(3):e5651 doi: 10.5867/medwave.2013.03.5651. 